\title{
A MULTI-AGENT BASED APPROACH FOR CHANGE MANAGEMENT IN MANUFACTURING ENTERPRISES
}

\author{
Mustafa Batuhan AYHAN ${ }^{1,2,{ }^{*}}$, Mehmet Emin AYDIN² Ercan ÖZTEMEL ${ }^{1,2}$ \\ ${ }^{1}$ Department of Industrial Engineering, Marmara University, Goztepe Campus, Kadikoy, Istanbul, TURKEY \\ ${ }^{2}$ Department of Computer Science \& Creative Technology, University of West of England, Bristol, BS16 1QJ,UK \\ ${ }^{*}$ Corresponding Author: e-mail: batuhan.ayhan@marmara.edu.tr Phone: +90216348 0292 Fax: +90 2163480293 \\ \{batuhan.ayhan,eoztemel\}@marmara.edu.tr,mehmet.aydin@uwe.ac.uk
}

\begin{abstract}
Change management becomes an unavoidable necessity for manufacturing enterprises. Since change in business processes carries significant impact on the performance of manufacturing companies, a change management model is definitely required to remain competitive. Moreover, utilizing agent based systems will provide computational provision and integrity to manage and measure the capabilities to follow the change in a progressive approach by employing the cooperation and collaboration properties of various agents helping for retrieval of the required information in a rapid way. Therefore, in this paper, a multi-agent based change management model is proposed to handle the changes in manufacturing enterprises. The model is validated through a case study done to measure the performance of change management capabilities in a manufacturing company. A sensitivity analysis on the results of this case study is also conducted to reveal the system reactivity to various parameters.
\end{abstract}

Keywords: Change Management, Agent Based Systems, Manufacturing, Sensitivity Analysis. 


\section{INTRODUCTION}

Change management is stated as one of the most important factors of successful leadership and management capabilities (Hayes, 2010). Since it does not have a single process structure to be implemented in for all kinds of enterprises, each organization should adapt itself to the change in accordance with its own dynamics. Manufacturing systems are the most affected ones by the changes given rise mostly in technology. Since the technology changes consistently, the manufacturing enterprises should follow and manage it. Otherwise, it is inevitable to back lag the technology and the product portfolio might become out dated. Moreover, technology is not the only factor that any manufacturing enterprise is affected by. Customer expectations, manufacturing processes, managerial techniques and environmental issues also change independently and progressively. In addition, the manufacturing enterprises should take into account of the latest innovation lines and trends, such as: intelligent product, product-driven automation, extended information systems, etc. Since these changes are not static and continuously evolve in time, it is a hard issue to follow them. Moreover dealing with each innovation is really burdensome and unnecessary. More important point is that, to evaluate the capability to follow and manage the change itself. In order to achieve this aim, a comprehensive change management model is vitally important for manufacturing enterprises. Hence, a generic model focusing on manufacturing is required to manage these changes and take their advantages.

In order to manage the change, the visualization, understanding and measurement of the success for all of the components are needed. Therefore, some change management models have been developed to gain this systematic approach. According to ADKAR (Hiatt, 2006) model, which is one of the most commonly known and used models, comprises 5 stages; Awareness, Desire, Knowledge, Ability, and Reinforcement to ascertain the change, successfully. Although it is a promising model, the main focus is on the personal perception and implementation of the change, not for the manufacturing functions. Other models including McKinsey 7-S Model, (Peters and Waterman, 2004) and Kotter's Model (Kotter, 1996), set various factors all co-working together to assess how the company can manage the change. However, a quantifiable metric system is missing to measure the success capability of this change management. Moreover, the main focus is for only the managerial aspect of the change in the existing models, but the manufacturing enterprises have their unique properties to be considered and monitored for the change management. A general framework is introduced by Ayhan (2010) to embrace a complete set of factors affecting the change in manufacturing industry. However, the model proposed does not have a computational provision and integrity in the corporate information system. Since the change management for manufacturing enterprises becomes more important progressively, some industrial solutions are introduced by software developer companies. For example, IBM SOA (Service Oriented Architecture) vertically integrates business processes with technical ones from the point of view of change management (Mesa, 2008). Although it is developed for the manufacturing domain, measuring methodology to assess the change management capability is shallow.

It is vital to integrate change management models into the corporate-wise information systems in which all managerial and operational functionalities are delivered. The corporate information systems are fullydistributed by nature, where the integrity of the systems remains as an important concern. Multi-agency is a relatively new and mature computational approach to tackle various issues across distributed systems without any concern of integrity. The approach is also useful to model various processes across the levels of enterprises. Monitoring and managing changes across enterprises on timely basis is not a trivial process, which requires periodical information retrieval from the entire system and filters the retrieved data to convert to sound information. In addition, the retrieved and filtered information needs to be aggregated withholding integrity and accuracy.

In this paper, a multi-agent based change management framework for manufacturing enterprises is proposed so that the level of change and its added-value can be monitored across the whole enterprises via collaborating agents, where each delivers an information search, retrieval and filtering functionalities for different organizational and operational duties. This multi-agent framework facilitates to overcome the drawbacks of the model introduced by Ayhan (2010) by providing computational effectiveness. The rest of the paper is organized as follow: the fundamentals of the change management model proposed for manufacturing enterprises is introduced in Section 2, while the multi-agent systems are briefed generally in Section 3. Section 4 presents an implementation of the multi agent framework and a case study including the sensitivity analysis follows prior to conclusions. 


\section{CHANGE FACTORS IN MANUFACTURING}

There are numerous factors leading to change in manufacturing enterprises, which are categorized into 5 main clusters in this model: Technological, Process-Based, Customer-Oriented, Managerial and Environmental change factors. The overall model is visualized in Figure 1, including sub-factors of each component and the nature of the relationship among them which leads to monitoring the state of the change. Since this model is designed for manufacturing enterprises, it includes some specific components. For example, "standards" under the "environmental change", inspects the international certifications related with the manufacturing systems. However, this model can easily be adapted to other systems by some modifications.

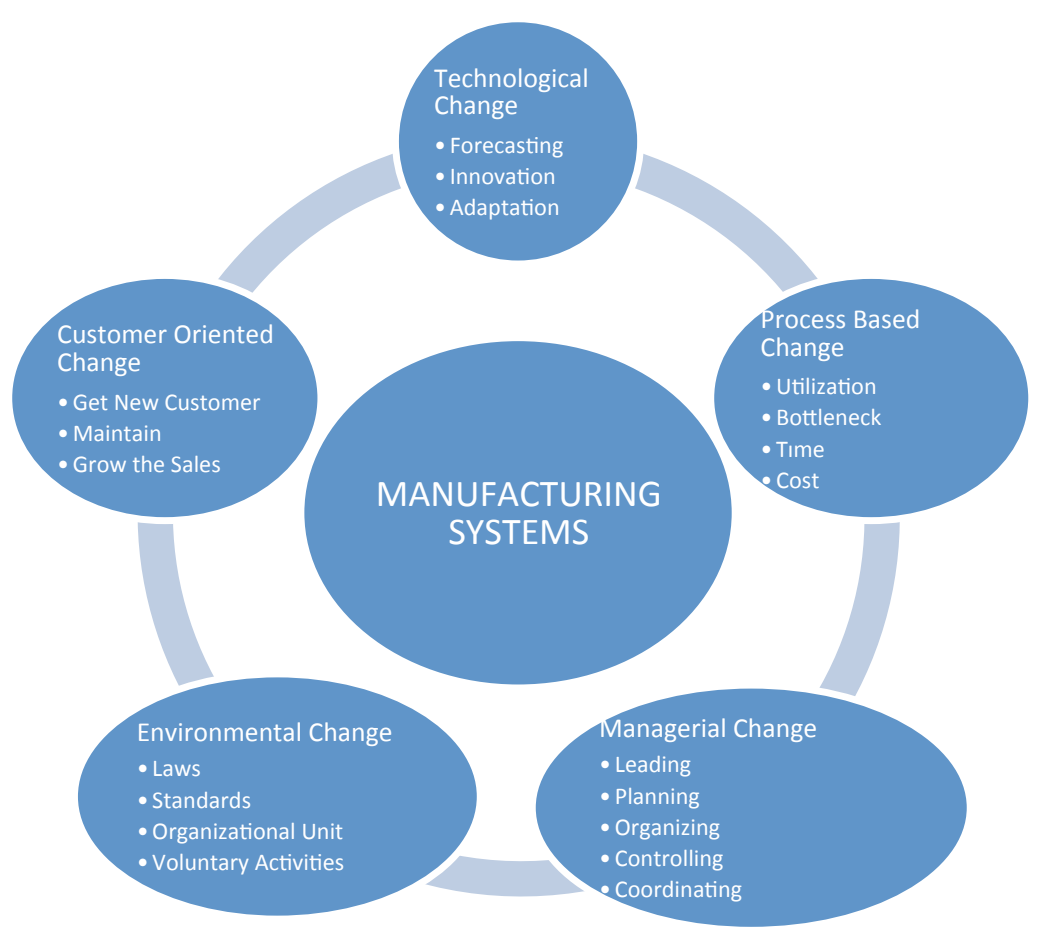

Figure 1 Change Management Model for Manufacturing Enterprises

\subsection{Technological Change}

Since the proper technological development can trigger the effectiveness of the production processes, it is crucial to decide on the best technology to invest and identify/estimate the return of investing the new technologies beforehand. Therefore, estimations on the benefits of the new technologies have to be accurate and precise. This clearly indicates the requirements for Technological Forecasting, which is defined as foreseeing the technological innovation, scientific developments, and estimating the benefits and occurrence time of scientific inventions (Oztemel and Ayhan, 2009). Technological forecasting methods are deeply studied in the literature and can be classified into 2 types; Numerical Data Based Techniques, and Judgment Based Techniques (See for examples, Martino, 1993; Meredith, 1995).

After deciding on the most proper technologies to invest, Product Innovation phase, which is defined as implementing new products or significant technological improvements in products (OECD, 1995), should take a role in releasing technologically innovated products. Since creating innovative products is another indication of following the technological change, it must be embedded in the change management model.

When innovative products are developed, Technological Adaptation, which is the penetration of the technological changes within the manufacturing system (Oztemel and Ayhan, 2008), is conducted as an adjustment of tools and equipments, adaptation of the employees, and the utilization of the knowledge level for the new products. Otherwise, technological forecasts and innovation studies cannot result properly. However, the literature originated from; technology acceptance model (Davis, 1989) and Technology Fit model (Goodhue and Thompson, 1995) generally depend on human psychology or the transfer of 
technologies. By the term of technological adaptation not only the human side but also the adaptation of tools and knowledge are taken into account.

\subsection{Process Based Change}

Process-based change, which is as important as the technological change, is defined as the adoption of technologically new or significantly improved production methods (OECD, 1995). A great impact by the new products on the market is not expected unless the process innovation follows. Traditionally, business process change is often measured in terms of lead time, service time, waiting time, and resource utilization (Stemberger and Jaklic, 2007; Tureteken and Schuff, 2007). Lee and Ahn (2008) propose a different method to assess the process improvement through a set of indicators, which can be adopted for the assessment of the success of manufacturing processes with some modifications (Oztemel and Ayhan, 2010). Average Worker Utilization indicates the performance of manufacturing processes in minimizing the frequencies of both idle-times and overtimes. In addition, minimizing the Bottleneck times for the manufacturing processes is also important for better performance with respect to some other measures such as productivity. Minimizing Unit Production Cost and Unit Production Time, of a certain production amount is the only way of maximizing the profit margin in a highly competitive market. Hence, evaluating the results of implementing a new manufacturing processes based on these indicators is required for monitoring the process change.

\subsection{Managerial Change}

Management idea, which was set on a scientific base by the studies of Frederick Taylor, was originally published in 1911 (Taylor, 2010). It is the attainment of organizational goals in an effective and efficient manner through planning, organizing, leading, and controlling organizational resources (Daft, 2008). In addition to these four functions, coordination of entities that form the life blood of the companies, is defined as much important as the previous functions by intra/inter communication channels for the staff and the supplier-customer line/relationship. Since the techniques used for management evolve in time (Smit and Vrba, 2007) due to technological and social changes, there is a need to monitor the changes that might occur in managerial functions.

Planning is to define the goals for the organizational performance in the future and to decide on the tasks and use of resources needed to attain these goals (Daft, 2008). Increasing the requirement of complex planning activities bears the transformation of plans, which reveals the need to monitor the changes that might occur in planning function of the manufacturing systems. Organizing is the activity of matching the tasks to employees. Although there are various organizational structures used throughout the ages (Drucker, 2007), it is important to screen this change in management perspective. Leading is the art of influencing individual or group activities towards the achievement of enterprise objectives. Leadership style is widely studied especially by the behavioral and social sciences (Wren and Bedeian, 2009; Robbins and Coulter, 2009), however, a monitoring scheme is required to analyze the changes that might occur in management function. Organizational Control is to check if everything happens in the way it was planned to happen. Since the manufacturing technologies evolve in time, controlling mechanisms also transform from the primitive case to the most contemporary techniques. Existing controlling methods can be viewed (Daft, 2008; Drucker, 2007; Robbins and Coulter, 2009) and the changes in these techniques should be monitored. Coordination, which is required to enhance the attainment of management objectives, can be sustained through the successful use of communication skills and detailed in the literature (Gomez-Mejia and Balkin, 2011; Hitt and Porter, 2011). Since the changes occur in manufacturing enterprises, communication styles also advance from the primitive case to the most contemporary ones. The changes in all these functions should be monitored and embedded to the whole change management system.

\subsection{Customer-Oriented Change}

The technological revolution has also led the changes in customer behavior. The traditional CRM models (Reddick, 2011) are not sufficient to manage the changes in customer profiles; the dynamic changing structure of consuming behaviors should also be regarded. Since the demands and profile of customers change spontaneously, the enterprise cannot control these changes but can follow and foresee future changes. In order to reflect these two aspects, the main aim of a monitoring system for the customer changes, should not only be following the changes but also leading the changes in customer demands 
(Peppers and Rogers, 2004). If the company can sustain its previous customers for the next terms then it is called to be successful to monitor the change and achieves higher Keeping Customer ratio. In order to indicate the success rate to trace the change in Getting New Customers Ratio by comparing the number of new customers with the previous ones, is also required. Finally, sales revenues to existing customers can be analyzed to find out the Growth Ratio. Based on these three metrics, the success rate of a company to manage the changes occurring in customer demands can be revealed.

\subsection{Environmental Change}

Changes in the ecological environment; such as global warming, climate change, decline of the natural resources would definitely affect the manufacturing systems. Although the manufacturing enterprises have nothing to do with these, it is vitally required to be aware of the environmental changes when trying to be compliant with the change as whole. For example, once the laws and international standards have changed due to the global warming and climate change, the firm must immediately adopt to these new changes, otherwise, the production process may be penalized. In order to continue manufacturing operations, they must comply with Laws, which are assumed to be revised due to the changes in the environment and can be found in the literature (Ministry of Environment \& Forestry, 2009). Even though the manufacturing company obeys the laws and the regulations, it is also important to satisfy the international environmental protection Standards (e.g. ISO14001), to indicate the capability to protect the environment. Furthermore, the existence of an Organizational Unit, which deals with the environmental changes, assesses the changes and makes strategic plans depending on the foresights of the changes, is an important indicator for successful environmental change management. Through performing the Voluntary Activities to protect the environment, not only the environmental change can be assessed more effectively, but also the company can increase the customer portfolio reputation by the Environmental Friendliness. Depending on these four factors, a monitoring system can be sustained for the environmental changes.

\section{MULTI-AGENT SYSTEMS \& MANUFACTURING INNOVATION}

An agent is defined as an entity that is able to carry out some tasks, and able to modify its environment usually to help a human user (Coppin, 2004; Fleury et al., 1999). By a more comprehensive definition, it is a computer system that is capable of independent autonomous actions in its environment.

It interacts with its environment, to meet its delegated objectives (Ma and Nakamori, 2005; Wooldridge, 2009). Here, the agent can make observations about its environment (perception), by using its own knowledge and beliefs; it can make decision about how to change the current state of environment (cognition) to achieve its own targets, and finally initiates and executes actions to make an aimed change within the environment (action).

The concept of multi-agent systems (MAS) is a well-known and reasonably mature collective intelligence approach with which a set of agents acting individually and collaboratively for solving problems (Ayhan et al., 2012). The idea of the multi agent systems is defined as to build up intelligent autonomous entities which constitute the teams to solve the problems in harmony and build a certain level of coordination to let each acting individual efficiently collaborate in solving the problems using their distributed intelligence (Aydin, 2012). Since they helped to realize important properties as autonomy, responsiveness, redundancy, and distributed approach, MAS are welcome in manufacturing and innovation. Through a comprehensive survey, potential manufacturing applications of MAS are introduced including Engineering Design (Mohebbi and Shafaei, 2012), Process Planning (Nejad et al., 2010), Production Planning, Scheduling \& Control (Lopez-Ortega et al., 2008), Enterprise Organization \& Integration, and Assembly Management (Monostori et al., 2006).

In a recent study, a multi agent based algorithm for personnel scheduling and rescheduling in a dynamic environment of a paced multi product assembly center is proposed (Sabar et al., 2012). Depending on the experimental results of that approach including four categories of autonomous agents namely; Production, Station, Coordinator, and Employee Agents, it produces high quality and efficient solutions in a short time compared with a simulated annealing algorithm. In another study an agent based material handling model is proposed for inventory management including three subsystems called Agent Based Communication System, Agent Based Material Handling System, and Agent Based Inventory Planning and Control System (Ito and Abadi, 2002). According to the results of the simulation with the agents, the prototype system 
shows promising results for inventory control. MAS is also used for reactive shop floor control including two cognitive agents called Supervisor and Meta-Object and three reactive agents called Cells, Products, and Resources (Roy et al., 2001). Since the multi agent platforms satisfy the modularity criterion, it is required to develop a re-configurable and adaptable shop floor control system as well as reactive to dynamic perturbations. According to their results, by the help of MAS, the reactivity is achieved with no competition among agents and the system only modifies what is necessary. All these applications of MAS to manufacturing flourish the idea of utilizing MAS in manufacturing and innovation applications.

In another perspective, to analyze the innovation and change management processes, Albino et al. (2006) carry out an agent based simulation in the industrial districts of Italy, which can be defined as a collection of heterogeneous, intelligent, and interacting agents living and operating in an environment. Although it clearly defines the agents, environment, interactions, actions and rules, the simulation study is performed through a set of manufacturing companies located in an industrial district. However, the requirement for a change management model focusing on manufacturing systems particularly is not fulfilled yet.

A demonstrative example of an agent based model to address the research question of how should manufacturers allocate resources to Research (New Product Generation) or Development (Incremental Products) projects is introduced (Garcia, 2005). In addition, the benefits of agent based models are summarized for manufacturing systems. Although four scenarios are created to run the agent based simulation and funds allocation ratios for research or development projects are computed, innovation and change management is something more comprehensive than only investigating the research and development project but also the management of customer, technology, and environment.

Since the innovation systems are viewed as complex systems, while the actors of system interact with each other, learn, adapt, reorganize, and expand their diversity, a multi agent model is built to simulate the technological innovation of manufacturers (Ma and Nakamori, 2005). Design parameters used by the producers, and performance parameters percepted by the consumers are thought as agents and according to simulation runs for different parameter values, the criteria to select the product are defined. However, the management procedure for change is neglected in this perspective. In other words, the changes occurring in design and performance parameter values are not the single units to be followed but the changes that might occur in other factors like managerial, or process based ones should be taken into account.

A recent paper has also provided another agent based simulation to help study enterprise's innovation behavior to remedy the insufficiencies of qualitative and traditional quantitative methods. Although the emergence and evolution of innovation are well studied, the simulation model lacks of action rules and different scenarios to be run (Wenrong and Xialong, 2011). However, another study about agent based models of innovation sets the basic reasons to deal innovation with multi agent systems. Since the innovation and change management systems have main difficulties with their dynamic structure, special nature of required knowledge, strong uncertainty, and heterogeneity; agent based models well overcome these problems suit these properties (Dawid, 2006).

When the new product development and design process are investigated as important parts of change management, there are various studies in the literature dealing different aspects of this phase. Chan et al. (2011.a) attempt to model the customer satisfaction for product development using genetic programming. Similarly, a new design process is presented for material delivery system in manufacturing environment (Kilic and Durmusoglu, 2012). Following, a fuzzy regression approach is proposed for effective product design that captures nonlinearity and fuzziness of the problem (Chan et al., 2011b.). Market segmentation of the new products developed based on consumers' requirements, which involves fuzziness, is recently proposed by Chan et al. (2012). Similarly, a generalized fuzzy least square regression approach is proposed to model the relationship in product development phase is also presented (Kwong et al., 2010). Although these fuzzy approaches are successful methods for product development phase, they are not adequate for the whole change management capability.

On the other hand, since there are many fuzzy applications to model the manufacturing processes, the other methods like neural networks and fuzzy system are also investigated to be implemented for change management. Although there are some good applications of fuzzy regression approach (Kwong et al., 2008) and genetic programming based on fuzzy system to modeling the manufacturing process (Chan et al., 2010), they take into consideration of two types of uncertainty; randomness and fuzziness. However, the change management for manufacturing requires the collaboration of each individual entity to achieve the ultimate goal. Therefore, additional to previous uncertainties, the uncertainty of the cooperation structure of each responsible part is important to be investigated. Hence, the multi agent systems are more convenient to analyze this relation. Therefore, in the next section a multi agent system is introduced to fulfill the 
requirement of an agent based change management model by utilizing the benefits and advantages of agent structures.

\section{MULTI-AGENT BASED CHANGE MANAGEMENT APPROACH}

\subsection{The Framework}

Suppose that, an enterprise has large archive of years and a running corporate solution, with which all operations are handled. The maintenance and issue handling operations are scheduled to happen during unpeak times. Innovation and change management can be considered as part of maintenance and performance handling operations, as a result, an automatic innovation and change management system is needed to be developed and deployed so that the whole system can be scanned and evaluated with respect to various measures including innovation level. Since the corporate system will be large and distributed, this sort of duties and operations should be devised smartly to make them sufficiently responsive and operative accordingly.

As change management model explained before requires some factors and sub-factors to be analyzed, a multi agent system will help cooperation and collaboration of these factors in order to assess the change management capability of a manufacturing system. According to basic change management model, each factor is responsible for the evaluation of the change management capability of technological, process oriented, customer oriented, managerial, and environmental changes. These factors can be nominated as different agents working collaboratively to compute the overall capability of the system. This approach can be justified by the multi-agent system proposed in the following.

A multi agent system framework is proposed to work in both hierarchical and heterarchical way so as to manage the change of a manufacturing enterprise. There are mainly two types of agents; chair and operational agents as reflected in Figure 2. The hierarchical way, the chair agent supervises the sub-chair agents at first and then the sub-chair agents supervise the operational agents. For the level of operational agents, they might work in harmony and collaboratively in a heterarchical manner to retrieve the required information.

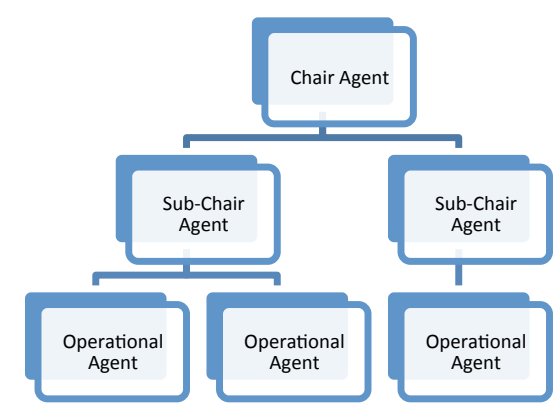

Figure 2: The hierarchy of multi agent system model (Ayhan et al., 2012)

Chair Agent, which aims to organize the rest of the team (tree) to work in harmony and collaborate on purpose, produces the final reports and presents to corresponding stages. The Sub-Chair Agents conduct both some organizational and operational duties. The Operational Agents are designed to search for relevant information through out of the resources/ infrastructures and produce the information expected from each of them. This hierarchical multi agent system model can be modified to change management model for manufacturing systems, which is explained in Section 2.

According to the 3 layer problem structure shown in Figure 3; the root/chair agent, which is denoted as C.M.A. (Change Management Agent), is responsible for the cooperation and coordination of the whole system through sub-chair agents; Technological Agent (T.A.), Process Agent (P.A.), Managerial Agent (M.A.), Customer Agent (Cu.A.), and Environmental Agent (Env.A.). C.M.A. also prepares the final reports on the success rate of change management and suggests advices for the company analyzed. 


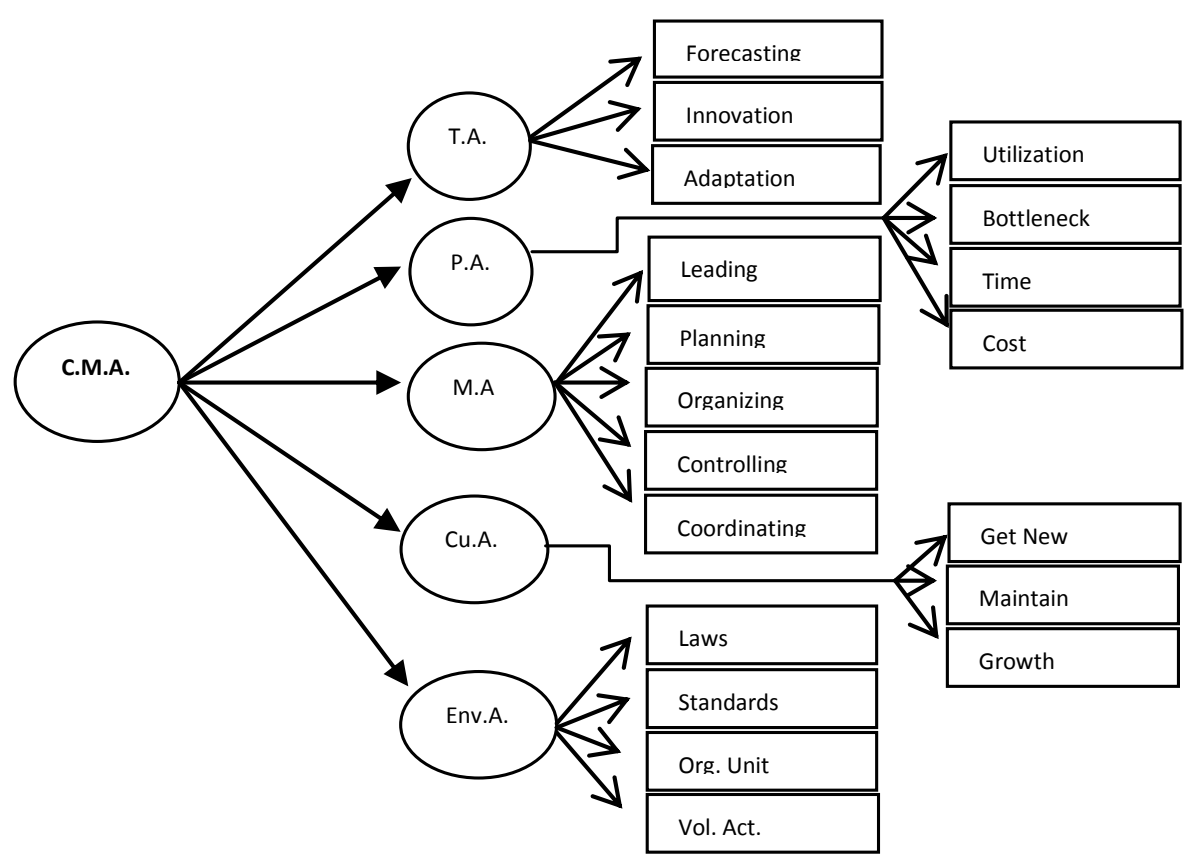

Figure 3: The problem structure of Agents hierarchy

According to MAS model of the change management for manufacturing enterprises shown in Figure 4, each of the sub-chair agents is both responsible for the cooperation of operational agents under its supervision and for the reporting of their operational results to one level up to the root agent. Sub-chair agents provide the information retrieval system for their operational agents and sustain the correct knowledge flow. The operational agents are mainly furnished with information retrieval and mining functionalities by default in order to enable them to search for the information needed through out of the corporate information systems. Every individual agent is also designed with a set of aims and objectives specific to the functionalities embedded in. These agents have the capability to negotiate with the other agents and to decide which agent is to conduct which part of the duty. Since they communicate and coordinate, the required information is achieved effectively.

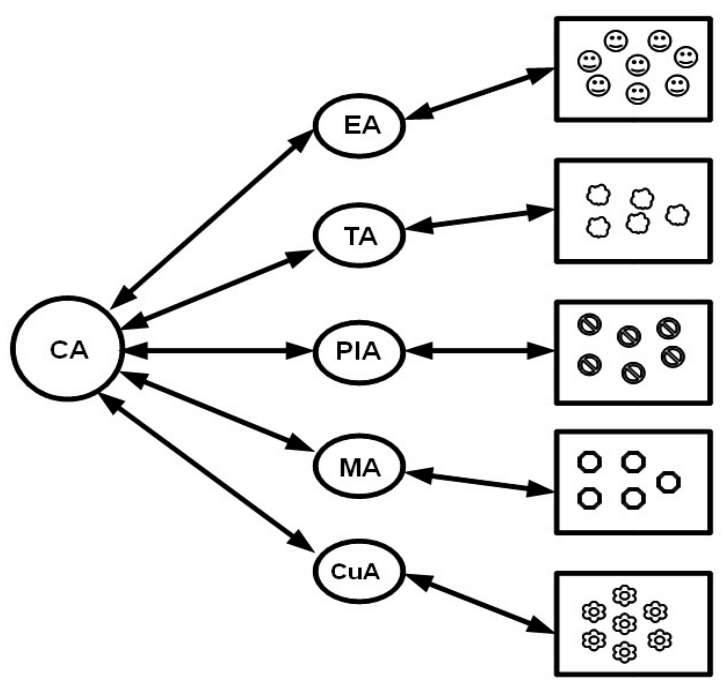

Figure 4: MAS model of Change Management 
Based on the tree structure of the problem given in Figure 3, the multi agent system is organized in the way depicted in Figure 4, where middle level agents are organizing and coordinating sets of equally skilled agents in the operational level. The agents following each branch of mid-level are furnished with different priorities and objectives. Each branch of duties in Figure 4 is delivered by a team of equally capable and skilled agents in a collaboration manner. The members of each team have direct communication within the team, but, external communication is not allowed except with the supervisor/sub-chair agent. The sub-chair initiates a list of tasks for a particular time period and shares with the agent team. Then, each agent picks up one particular task to start, once finished, it submits the information retrieved as the result of its action, and then, negotiates if there is any other task to do. This is repeated by each agent until the whole list is completed. For example, the sub-chair agent called Technology agent, T.A for short, orchestrates a team of operational agents to complete all tasks related to Forecasting, Innovation and Adaptation, where the tasks are created and dispatched to the agents based on computational time consumption level. For instance, adaptation can be done by more agents while forecasting would be done by less. The collective intelligence cultivated and harvested in this architecture originates through the structure soft hierarchy, where the information retrieved and the knowledge produced by each operational agent collected by sub-chairs and normalized accordingly and then, finalized by the Chair agent.

\subsection{Collaboration and Task Delivery}

Sub-chair agents deliver collaboration among the operational agents and merge the returned results into a unified form and send it back to the Chair agent, which orchestrates the whole model. Sub-chair agents create sets of tasks and produce lists for each set and share with the operational agents supervised. A task is made of three components as following:

$$
\tau(\boldsymbol{t})=\left\{\varphi_{i}, \eta_{j}, o_{j}\right\}
$$

where, $\tau(t)$ is a task, $t$ is an index for the tasks included in a list, $\varphi_{i}$, is the $i$ th functionality to be delivered using input set of $\eta_{j}$ to produce output set of $o_{j}$. A list of tasks, $\mathfrak{\Im}_{\boldsymbol{k}}=\left\{\tau_{\boldsymbol{t}} \mid \boldsymbol{t}=1, \ldots, \boldsymbol{T}\right\}$, generated by each sub-chair agent and shared with the team works under its supervision. Then, each team starts acting to deliver the tasks as required. Each input set, $\eta_{j}$, consists of all relevant information required for taking action including the part of the enterprise-wise IT system to search through and the expected deadline for the action to take. Once information gathered and processed with corresponding functionality, $\varphi_{i}$, it produces an output set, $o_{j}$, to be returned to sub-chair agent. The functionalities which are conducted by the agents are of a set of functions, $\Phi=\left\{\varphi_{\boldsymbol{l}} \mid \boldsymbol{l}=1, \ldots, \boldsymbol{L}\right\}$, created to be used once needed across the whole IT system, where each sub-chair is allowed to be responsible of a subset of them. The teams of operational agents deliver all the tasks in collaboration, which is organised in a bi-directional ring-topology (Aydin et al, 2013) as depicted in Figure 5.

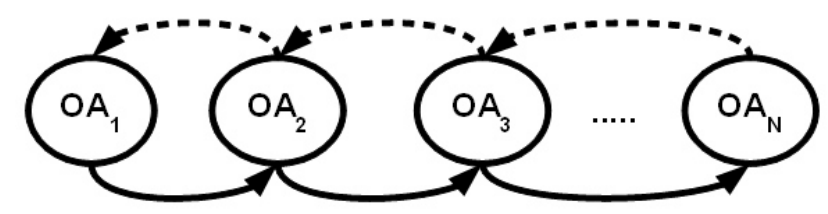

Figure 5: Collaboration among operational agents (OA)

Let $N$ be the number of operational agents forming up a team of agents under supervision of a sub-chair. The collaboration among each team is conducted for sharing the list of tasks completed and waiting yet to be done. Also, let $O A_{j}$ be agent $j$, which exchanges information with only two adjacent neighbors; $O A_{j-1}$ and $O A_{j+l}$, where $j=1, \ldots, N$. A cycle of information sharing consists of forward and backward phases, where forward phase is initiated by $O A_{1}$ sending its up-to-date list of completed tasks to $O A_{2}$, and then it is forwarded to $O A_{3}$ so as to aggregate the updated information by passing the messages one after another until it reaches the end of the chain, $O A_{N}$. The forward phase ends with the aggregated list at $O A_{N}$, here $O A_{N}$ 
initiates the backward phase to let all other agents know the most up-to-date list, (Figure. 5). Information sharing cycles are repeated until the tasks in the list are all completed.

The whole information gathered is put together as the union of all findings by the agent teams. Sub-chair agents collect all outputs, $\boldsymbol{O}_{i}=\left\{\boldsymbol{o}_{1}, . ., \boldsymbol{o}_{j}, . ., \boldsymbol{o}_{N_{i}}\right\}$, and combine and refine them into one knowledge/information unit using the following union function:

$$
I=\bigcup_{i=1}^{C} \bigcup_{j=1}^{N_{i}} O_{i, j}
$$

where $I$ is the ultimate produced information/knowledge retrieved and combined across the whole system. $C$ is the number of sub-chair coordinating agents and $N_{i}$ is the size of team of agents working under supervision of $i$ th sub-chair. $\boldsymbol{O}_{\boldsymbol{i}, \boldsymbol{j}}$ is the output produced by agent $j$ within team $i$.

\subsection{Numerical Results}

The multi-agent approach introduced above has been implemented for monitoring the change and measuring the change capability of a manufacturing company within time period of 3 years between 2006 and 2009. A simulation has been devised and conducted using "NetLogo 5.0.3" for this purpose using the data sets used for the related works published before in Ayhan et al. (2013), where a quantitative measurement index has been introduced to work out the change and innovation capability of the manufacturing environment in the case. However, there is no computational model implementing this index and the numerical calculations are beyond the scope of this paper. Relevant computational details can be found in the literature (Oztemel and Ayhan, 2008; Oztemel and Ayhan, 2009; Oztemel and Ayhan, 2010; Oztemel and Ayhan, 2011; Ayhan, 2010; Ayhan and Oztemel, 2011). The multi-agent model introduced above has been simulated to retrieve the relevant information from such a system to calculate the quantitative index across such a manufacturing enterprise.

It is observed that since the beginning of 2009, the production manager had changed and welding technology had been transformed to a new technology across the company. This has been taken as starting point to measure how much change has been applied to the manufacturing process with all other related business and environmental functionalities. The corporate solution working across the enterprise is made of two distributed independent, but, collaborating sites; site A and site B. Taking all these circumstances into account, the following development has been made to achieve a computational model for calculating the innovation index introduced in Ayhan et al. (2013).

Each main branch of the relationship tree has been tackled with a team of agents coordinated by a subchair agent accordingly. The team for technological changes is a team of 5 agents conducting a task list of all operations dealing with Forecasting, Innovation, and Adaptation in both sites of the enterprise. 2 agents are allocated to site $\mathrm{A}$ and 3 to the site $\mathrm{B}$, where site $\mathrm{B}$ has more data and information to scan.

The results provided by these agents are collected by TA sub-chair agent, averaged to find out the effect of each type of operation on technological change as shown in Table 1. The weights for the operation types are already known, determined based on a questionnaire performed through the specialists from both the academic and industrial representatives who expertise in this subject. According to weight assignments, the operational agents supervised by technological sub-chair agents are shared within the related tasks. This is also consistent with the difficulty of the work to be performed. In other words, since adaptation is much more difficult than forecasting, more agents are assigned to adaptation task. On the other hand, once the agents conduct their tasks they interact accordingly and check if there is any task awaiting to complete.

Table 1: Technological Change

\begin{tabular}{|l|r|r|}
\hline Operations & Weight & Capability (\%) \\
\hline Forecasting & 0.29 & 49.62 \\
\hline Innovation & 0.33 & 62.14 \\
\hline Adaptation & 0.38 & 68.12 \\
\hline Technological Change (\%) & $\mathbf{6 0 . 7 8}$ \\
\hline
\end{tabular}


The change in the process management is conducted under coordination of Process agent to monitor and measure the change in the Utilization, Bottleneck, Time and Cost operations. In order to set the "physical" connection between the data presented in Tables 1 to 7 and the real data acquired from the processes of the manufacturing enterprise a short example of data fusion can be explained for "Process Change". General information about the manufacturing process of the company investigated is given in Table 2 and Table 3 .

Table 2: General information for the manufacturing processes for 2006 and 2009

\begin{tabular}{|l|r|r|}
\hline Information & $\mathbf{2 0 0 6}$ & \multicolumn{1}{|c|}{$\mathbf{2 0 0 9}$} \\
\hline Total \# of Products & 268,321 & $1,308,588$ \\
\hline Total \# of Working Days & 230 & 230 \\
\hline Total \# of Workers & 7 & 28 \\
\hline \# of Shifts & 1 & 2 \\
\hline Total Production Cost (TL) & 700,000 & 175,000 \\
\hline
\end{tabular}

Table 3: Detailed information for the manufacturing processes for 2006 and 2009

\begin{tabular}{|c|c|c|c|c|c|c|c|c|c|}
\hline \multirow[t]{3}{*}{ Work Center } & \multicolumn{2}{|c|}{ \# of Machines } & \multicolumn{3}{|c|}{ \# of Workers } & \multicolumn{2}{|c|}{$\begin{array}{l}\text { Standard Time } \\
\text { (sec.) }\end{array}$} & \multicolumn{2}{|c|}{ Daily Product } \\
\hline & \multirow[t]{2}{*}{2006} & \multirow[t]{2}{*}{2009} & \multirow[t]{2}{*}{2006} & \multicolumn{2}{|l|}{2009} & \multirow[t]{2}{*}{2006} & \multirow[t]{2}{*}{2009} & \multirow[t]{2}{*}{2006} & \multirow[t]{2}{*}{2009} \\
\hline & & & & $\begin{array}{l}\text { Day } \\
\text { Shift }\end{array}$ & $\begin{array}{l}\text { Night } \\
\text { Shift }\end{array}$ & & & & \\
\hline Cutting & 1 & 1 & 1 & 1 & 1 & 3.50 & 3.50 & 1166 & 5690 \\
\hline Grinding & 1 & 1 & 1 & 1 & 1 & 5.00 & 5.00 & 1166 & 5690 \\
\hline Welding & 3 & 6 & 1 & 4 & 4 & 40.50 & 21.38 & 1166 & 5690 \\
\hline Testing & 2 & 2 & 1 & 2 & 2 & 10.00 & 10.00 & 1166 & 5690 \\
\hline Plastic Coating & 1 & 1 & 2 & 2 & 1 & 43.33 & 15.00 & 583 & 2845 \\
\hline Packaging & 1 & 1 & 1 & 5 & 4 & 23.00 & 23.00 & 1166 & 5690 \\
\hline
\end{tabular}

Based on this information, 6 agents coordinated by Process Agent are scanned for both sites and collaborated to complete the task list for the Utilisation, Bottleneck, Unit Production Time, and Cost of the system, accordingly. Since both sites A and B host all of these four tasks, the allocation of 6 agents are performed according to the importance degree of them. As shown in Table 4, since the weight of cost and utilization tasks are more than the others, 4 agents beneath under Process sub-chair agent, are recruited to calculate the unit production cost and the utilization of the system, two for each task. Remaining two agents are shared between bottleneck and unit production time tasks, one for each. In order to clarify the working scheme of the agents, the calculation methodology for unit production time is explained in detail. It is simply calculated by adding up the standard times of the serial work centers. Hence the unit production times are found as 125.33 and 77.88 seconds for 2006 and 2009, respectively. The details of the calculation methods for other agents can be found in the literature (Ayhan and Oztemel, 2011). After delivery of each task, the agents also compare the improvement on the mentioned indicators, where the results of these improvements are collected, weighted and averaged by sub-chair agent to assess the process change capability which is found as $47.95 \%$ as shown in Table 4 .

Table 4: Process Change

\begin{tabular}{|l|r|r|r|r|}
\hline Operations & \multicolumn{1}{|c|}{$\mathbf{2 0 0 6}$} & $\mathbf{2 0 0 9}$ & Improvement & \multicolumn{1}{c|}{ Weight } \\
\hline Utilization & $\% 47$ & $\% 45$ & $\% 0.00$ & 0.26 \\
\hline Bottleneck & 1.65 & 0.79 & $\% 52.03$ & 0.24 \\
\hline Time (sec.) & 125.33 & 77.88 & $\% 37.86$ & 0.21 \\
\hline Cost (TL) & 2.61 & 0.13 & $\% 94.87$ & 0.29 \\
\hline \multicolumn{2}{|l}{ Process Change(\%) } & & & $\mathbf{4 7 . 9 5}$ \\
\hline
\end{tabular}


The Managerial sub-chair agent is made responsible to calculate the change capability of the enterprise regarding the managerial operations. To do these, it coordinates its agent team of 8 agents to 5 management operations. Since these management functions are required in both production sites A and B, the allocation of these 8 agents are performed due to their relative importance. Based on the weights shown in Table 5, 6 agents are equally-shared between planning, leading, and controlling functions, assigning 2 agents to each. The rest of 2 agents are equally shared between organization and coordination functions. The agents are responsible to analyze the planning operation, once finished, they submit the information retrieved as the results of their actions, and then, negotiate if there is any other task to do within the managerial sub-chair agent. This is performed by each agent team until the whole task list of managerial sub-chair agent is completed. The collective intelligence cultivated and harvested in this architecture is fed back to Managerial sub-chair agent and the capability is found as $47.87 \%$ as shown in Table 5.

Table 5: Managerial Change

\begin{tabular}{|l|r|r|}
\hline Operations & Capability & Weight \\
\hline Planning Function & $\% 35.48$ & 0.25 \\
\hline Organization Function & $\% 9.68$ & 0.17 \\
\hline Leading Function & $\% 87.10$ & 0.22 \\
\hline Controlling Function & $\% 70.51$ & 0.21 \\
\hline Coordinating Function & $\% 22.58$ & 0.15 \\
\hline Managerial Change (\%) & \multicolumn{2}{|c}{} \\
\hline
\end{tabular}

Since the investigated manufacturing company sells all of its products through a marketing company embedded in the same enterprise group, they do not have any data about the customer portfolio. They only have the data about the number of products sold, but nothing about customer information. Hence, the Customer sub-chair agent cannot provide any required information for collaborating the operational agents supervised. Therefore this part is omitted from the whole process but signifying an important future research area.

As explained before, Environmental sub-chair agent is responsible to analyze the capability of the enterprise to follow the changes occurring in the environment. Since the operations under this sub chair agent are relatively simple to previous tasks under other sub chair agents, a team of 3 agents are adequate to be assigned. They investigate whether the activities by the enterprise are complying the laws set to protect the environment, having certificates for international standards, establishing an organizational unit to follow the environmental change, and performing voluntary activities to protect the environment. Since all of these tasks should be performed in both sites $\mathrm{A}$ and $\mathrm{B}$ and site $\mathrm{B}$ has more tasks to do, 2 operational agents are recruited to deliver these tasks for the required information for site $\mathrm{B}$ and 1 agent for site $\mathrm{A}$. When completed, they submit the information retrieved as the result of the action to the sub-chair agent, and then, negotiates if there is any other task to do within the environmental sub-chair agent. Consequently, supported by the cooperation of the agent team, Environmental change capability is calculated and founded as $27.15 \%$ as shown in Table 6

Table 6: Environmental Change

\begin{tabular}{|l|r|r|}
\hline Operational Tasks & Capability & \multicolumn{1}{|c|}{ Weight } \\
\hline Laws & $\% 100$ & Compulsory \\
\hline Standards & $\% 0$ & 0.42 \\
\hline Organizational Unit & $\% 45$ & 0.37 \\
\hline Voluntary Activities & $\% 50$ & 0.21 \\
\hline $\begin{array}{l}\text { Environmental } \\
\text { Change (\%) }\end{array}$ & & $\mathbf{2 7 . 1 5}$ \\
\hline
\end{tabular}

As the last, Change Management Agent, which is the root/chair agent, is responsible to gather all the information from its supervised sub-chair agents and authority to prepare the results about the change management of the manufacturing company. Depending on the weight assignments, Change Management Agent finds out the change management capability as $49.63 \%$ as shown in Table 7 . However, since the customer sub-chair agent cannot cooperate properly, the results of other 4 sub-chair agents averaged. 
Table 7: Change Management

\begin{tabular}{|l|r|r|}
\hline Sub-Chair Agents & Capability & Weight \\
\hline Technological A. & $\% 60.78$ & 0.28 \\
\hline Process A. & $\% 47.95$ & 0.21 \\
\hline Managerial A. & $\% 47.87$ & 0.17 \\
\hline Customer A. & Not Applicable & 0.23 \\
\hline Environmental A. & \%27.15 & 0.11 \\
\hline $\begin{array}{l}\text { Change } \\
\text { Management } \\
\text { Capability }\end{array}$ & & $\mathbf{\% 4 9 . 6 3}$ \\
\hline
\end{tabular}

Through the agent based change management analysis, operational agents cooperate together and the sub-chair agents coordinate the results of the operational agents to find out the overall change management capability of the enterprise. Since the customer agent lacks of information to perform the analysis, and the whole evaluation method depends on many variables, a sensitivity analysis of these parameters is discussed in the next section.

\subsection{Sensitivity Analysis and Discussions}

As noted previously, the customer sub-chair agent cannot cooperate properly due to insufficient information for this case study. However, it will be beneficial to determine the effects of operational agents, beneath the customer sub-chair agent. Therefore to analyze the sensitivity of the overall change management capability, relative weights of these particular operational tasks and their capabilities found by the case study, are tabulated in Table 8.

Table 8: Relative Weights and Capability values of each Operational Tasks

\begin{tabular}{|c|c|c|c|c|c|}
\hline \multirow{2}{*}{$\begin{array}{l}\text { SUB-CHAIR } \\
\text { AGENTS }\end{array}$} & \multirow{2}{*}{$\begin{array}{l}\text { OPERATION } \\
\text { AL TASKS }\end{array}$} & \multicolumn{3}{|c|}{ CAPABILITY } & \multirow{2}{*}{$\begin{array}{l}\text { WEIG } \\
\text { HT }\end{array}$} \\
\hline & & $\begin{array}{l}\text { BASE } \\
(\%)\end{array}$ & $\begin{array}{l}\text { MIN } \\
(\%)\end{array}$ & $\begin{array}{l}\text { MAX } \\
(\%)\end{array}$ & \\
\hline \multirow{3}{*}{$\begin{array}{l}\text { TECHNOLOGIC } \\
\text { AL AGENT }\end{array}$} & Forecasting & 49,62 & 0 & 100 & 0,0812 \\
\hline & Innovation & 62,14 & 0 & 100 & 0,0924 \\
\hline & Adaptation & 68,12 & 0 & 100 & 0,1064 \\
\hline \multirow{4}{*}{$\begin{array}{l}\text { PROCESS } \\
\text { AGENT }\end{array}$} & Utilization & 0 & 0 & 100 & 0,0546 \\
\hline & Bottleneck & 52,03 & 0 & 100 & 0,0504 \\
\hline & Time (sec.) & 37,86 & 0 & 100 & 0,0441 \\
\hline & Cost (TL) & 94,87 & 0 & 100 & 0,0609 \\
\hline \multirow[b]{5}{*}{$\begin{array}{l}\text { MANAGERIAL } \\
\text { AGENT }\end{array}$} & Planning F. & 35,48 & 0 & 100 & 0,0425 \\
\hline & $\begin{array}{l}\text { Organization } \\
\text { F. }\end{array}$ & 9,68 & 0 & 100 & 0,0289 \\
\hline & Leading F & 87,10 & 0 & 100 & 0,0374 \\
\hline & Controlling $\mathbf{F}$ & 70,51 & 0 & 100 & 0,0357 \\
\hline & $\begin{array}{l}\text { Coordinating } \\
\text { F. }\end{array}$ & 22,58 & 0 & 100 & 0,0255 \\
\hline \multirow[b]{3}{*}{$\begin{array}{l}\text { CUSTOMER } \\
\text { AGENT }\end{array}$} & Get New & $\begin{array}{r}\text { Not } \\
\text { Applicable }\end{array}$ & 0 & 100 & 0,0759 \\
\hline & Maintain & $\begin{array}{r}\text { Not } \\
\text { Applicable }\end{array}$ & 0 & 100 & 0,0897 \\
\hline & Grow & $\begin{array}{r}\text { Not } \\
\text { Applicable } \\
\end{array}$ & 0 & 100 & 0,0644 \\
\hline ENVIRONMENT & Standards & 0 & 0 & 100 & 0,0462 \\
\hline
\end{tabular}




\begin{tabular}{|l|l|r|r|r|r|} 
AL AGENT & $\begin{array}{c}\text { Organizationa } \\
\text { I Unit }\end{array}$ & 45,00 & 0 & 100 & 0,0407 \\
\cline { 2 - 5 } & $\begin{array}{c}\text { Voluntary } \\
\text { Activities }\end{array}$ & 50,00 & 0 & 100 & 0,0231 \\
\hline
\end{tabular}

The relative weight of a particular operational task is calculated by multiplying the relative weight of the related sub-chair agent and the one of the inspected operational task. That is; the particular relative weight of Forecasting task (0.0812) is found by the multiplication of the weight of Technological sub-chair agent (0.28) with the weight of Forecasting task (0.29) within the branch of this sub-chair agent.

In addition, Table 8 presents the base values of the capabilities of the operational tasks, which are gathered through the case study. Adjacent to these Base Values the minimum and maximum possible values are given for these operational tasks. In other words, the maximum and the minimum values for the success rate of these the operational tasks can be $100 \%$ and $0 \%$, respectively.

The Customer sub-chair agent is left out of analysis due to insufficient information, but, the impact of operational tasks coordinated by this sub-chair agent need to be calculated. For this reason, the base values of the related operational tasks can be assumed as " $50 \%$ ". At this step; to evaluate the effect of the changes, an agent based simulation and modeling program called "NetLogo 5.0.3" is utilized. By the help of this software, reflecting the changes occur in the input variables is adequate to make the overall analysis repetitively. This program will also be helpful to make the sensitivity analysis of each operational agent for next steps. Depending on the assumption of " $50 \%$ " capability for the related customer operational tasks, the Change Management Capability is calculated as $49.71 \%$. As it is seen, when the Customer Sub-chair agent is in consideration and the capability values of all of customer operational tasks are assumed as $50 \%$, the change management capability does not significantly change. But still we do not have the adequate information about the sensitivity of these agents. Therefore to perform the sensitivity analysis of all operational tasks, the following Tornado Diagram could be helpful. 


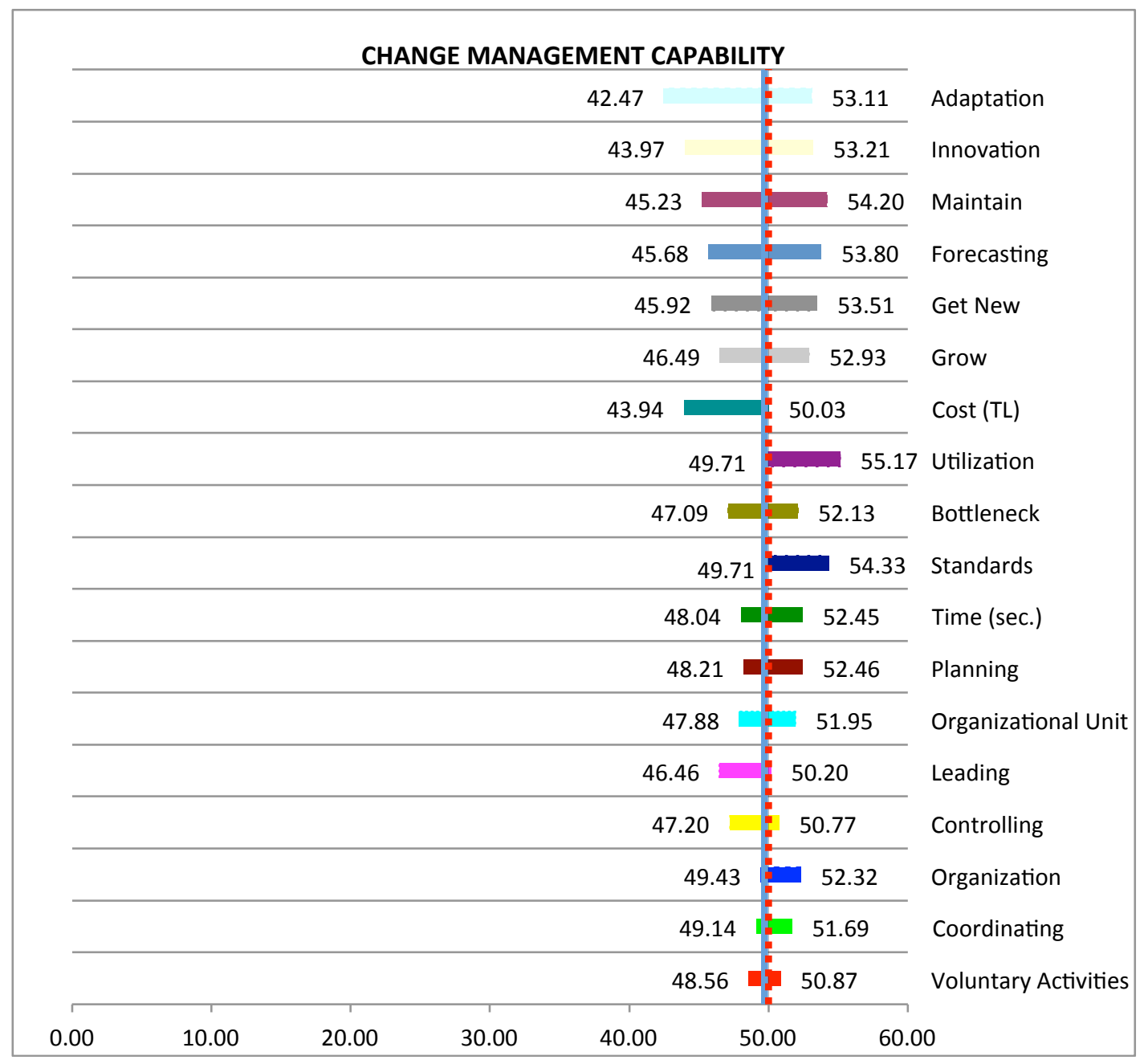

Figure 6: Tornado Diagram for the sensitivity analysis of the related operational tasks

This diagram is depicted as calculating the overall change management capability by changing the base success rate of a particular operational task to minimum and maximum values while setting the other values remaining constant. That is, while remaining the other values at their base values, if the "Adaptation" value becomes " $0 \%$ " or " $100 \%$ ", the overall change management capability will become " $42.47 \%$ " or " $53.11 \%$ ", respectively. Figure 6 also illustrates the following inferences of the change management analysis.

First of all, 18 operational tasks are listed in descending order according to their relative weights. Note that, since "Law", mentioned in both Figure 3 and Table 6, is a compulsory requirement, it is out of concern of the sensitivity analysis. Due to this diagram, "Adaptation" and "Voluntary Activities" have the most and least effect on Change Management capability, respectively.

$>$ The red dashed line sets the limit to $50 \%$ representing the average capability for the change management. The blue line corresponds to the "Change Management Value (49.71\%)" according to the base level values of the operational tasks and assuming success rates of the operational tasks of customer sub-chair agents as $50 \%$. Since the blue line is on the left of the red dashed line, the manufacturing company is strongly advised to improve its performance with respect to change management capability.

To improve the change management capability, the company should pay attention to the most sensitive operational tasks (Adaptation, Innovation, and Maintaining tasks). However, it is 
remarkable that, the "Utilization Task", only itself, can increase the capability to $55.17 \%$. Similarly, "Standards Task" can also increase the capability to $54.33 \%$, by only changing its level to maximum level. This is because of the reason that, in the base level analysis, both operational tasks' values are $0 \%$. So, any increase in these agents will definitely affect the overall score.

$>$ On the contrary, any improvement in "Cost" and "Leading" operational tasks can particularly only increase the change management capability to $50.03 \%$ and $50.20 \%$ respectively. This is because of in the base value analysis, values of "Cost" and "Leading" tasks are $94.87 \%$ and $87.10 \%$ as shown in Table 8 . That is, they are close to maximum values and it is not so worthy to deal with them as they cannot improve the overall score as much.

When the overall analysis is interpreted with a management perspective, the multi agent based change management is required and useful for the following reasons. First of all, since the changes occur in many different areas, the coordination of capabilities of them can be sustained with a multi agent structure. Secondly, the changes might occur in every mentioned area progressively, so the analysis can be required repetitively. Hence for the management level of the enterprise, it can be handled with a comprehensive model as represented. In addition, by implementing this model, the management can retrieve the required information easily and be aware of the factors that may be obstacles to manage the change.

Briefly, the main contribution of this model can be stated as developing a multi-agent-based change management model for manufacturing enterprises, which can handle the five main areas. Incorporating the agent-based structure, it becomes easy to find out the related information and to make the analysis repetitively without interrupting the manufacturing process. Moreover with the sensitivity approach, the main issues to take into account are easily seen.

Beyond these particular inferences from this analysis, it is noted that the overall score also depends on weights of these agents as well as their values. So in the next step of this study, minimum and maximum values of the relative weights can be gathered through Analytic Hierarchy Process. Depending on that, another sensitivity analysis can be carried on to enlighten system reactivity. However, the questionnaire is deliberatively performed through the specialists from academia and industry to prevent a bias that might occur from any of the participants. Since the perceptions and assessments of each cluster may differ, both sides are investigated. Hence the questionnaire approach becomes more credible.

In addition, since the overall change management capability depends on so many factors, it can easily change from time to time. Hence it is required to observe this capability to survive in the competitive and innovative market structure, it is better to set up a software program or mounting change management module to existing ERP (Enterprise Resource Planning) programs. Sustaining this foundation will enable the company to check its change management capability periodically without interrupting its daily routine activities. Once the manufacturing system and their data related with this analysis are given to software, by the help of agents, the change management capability can be calculated easily. Moreover, providing the feedbacks from the analysis, the company can easily see the weaknesses and the points to be improved. Since developing such an expert system operating with intelligent agents is essential to the manufacturing systems, it would be an interesting research area as the further steps of this study.

\section{CONCLUSION}

In this paper, a multi agent-based change management approach is introduced with support of numerical results. The most motivating reason to implement an agent-based approach for the change management is to devise and configure a computational model for an automatic change monitoring and management system exploiting the synergy of simplified computing techniques furnished in each of system components. Since some of the change elements require the same information with others, to prevent the retrieval of same data for many times, operational agents can communicate and cooperate with each other. By the coordination of operational and sub-chair agents, computational efficiency of the whole system increases as it leads to repetitive and continuous checks for change management.

In addition since the overall change management capability depends on various factors, a sensitivity analysis is conducted, and the results of this analysis are demonstrated using a tornado diagram, where the 
relative impact of each change is reflected in overall change score to identify the most important factors of the change.

As the further steps of this study, performing a sensitivity analysis dealing with the relative weights and utilizing Analytic Hierarchy Process is directed. This will enable to check the responsiveness of the analysis from both ways: the values and the relative weights. Beyond that mounting a module calculating the change management capability to ERP programs is suggested. This module can enable the evaluation of this capability without interrupting the daily routines by the help of intelligent agents.

\section{REFERENCES}

Albino, V., CarbonaraA, N., Giannoccaro, I., 2006. Innovation in Industrial Districts: An Agent Based Simulation Model, International Journal of Production Economics, Vol. 104, Issue 1, pp 30-45.

Aydin, M.E., 2012. Coordinating metaheuristic agents with team intelligence, Journal of Intelligent Manufacturing, Vol. 23, Issue 4, pp. 991-999.

Aydin, M. E., Safdar, G.A., and Aslam, N., 2013. "A novel learning-based spectrum sensing technique for Cognitive Radio Networks", 27th International Conference on Advanced Information Networking and Applications (AINA 2013), Barcelona, Spain, 25-28 March 2013, pp:505-510.

Ayhan, M. B., 2010. Development of a change management model for manufacturing systems, Ph.D. dissertation, Marmara University, Goztepe, Istanbul, Turkey, October 2010.

Ayhan, M. B., Oztemel, E., 2011. "A Methodology for Measuring Product Innovation: A Case Study for a Manufacturing System", International Journal of Manufacturing Technology and Management, Vol. 24, Nos. 1/2/3/4, pp.139-152.

Ayhan, M. B., Aydin, M. E., Oztemel, E., 2012. Collective Intelligence for Monitoring Innovation and Change in Manufacturing Industry, International Conference of Manufacturing Engineering and Engineering Management 46 July 2012, London, UK.

Ayhan, M.B., Oztemel, E., Aydin, M.E., Yue, Y., 2013. A quantitative approach for measuring process innovation: a case study in a manufacturing company, International Journal of Production Research, Published Online doi: $10.1080 / 00207543.2013 .774495$

Chan, K.Y., Kwong, C.K., Tsim, Y.C., 2010. A genetic programming based fuzzy regression approach to modelling manufacturing processes, International Journal of Production Research Vol. 48 (7), pp. 1967-1982.

Chan, K.Y., Kwong, C.K., Wong, T.C., 2011a. Modelling customer satisfaction for product development using genetic programming, Journal of Engineering Design Vol. 22 (1), pp. 55-68.

Chan, K.Y., Kwong, C.K., Dillon, T.S., Fung, K.Y., 2011b. An intelligent fuzzy regression approach for affective product design that captures nonlinearity and fuzziness, Journal of Engineering Design Vol. 22 (8), pp. 523-542.

Chan, K.Y., Kwong, C.K., Hu, B.Q., 2012. Market segmentation and ideal point identification for new product design using fuzzy data compression and fuzzy clustering methods. Applied Soft Computing Vol. 12(4), pp. 1371-1378.

Coppin, B., 2004. Artificial Intelligence Illuminated, Johns and Bartlett Publishers, USA, ${ }^{\text {st }}$ Edition.

Daft, R., 2008. New Era of Management, Thompson South Western, 2nd ed. NY, USA.

Davis, F., 1989. Perceived usefulness, perceived ease of use, and user acceptance of information technology, MIS Quarterly, vol. 35, pp. 227-230.

Dawid, H., 2006. Chapter 25 Agent Based Models of Innovation and Technological Change, Handbook of Computational Economics, Vol. 2, pp. 1235-1272.

Drucker, P., 2007. The Practice of Management, Elsevier Publisher, Drucker Collection Edition ed. Oxford, UK.

Fleury, G., Goujon, J-Y., Gourgand, M., Lacomme P., 1999. Multi-agent approach and stochastic optimization: Random events in manufacturing systems, Journal of Intelligent Manufacturing, Vol. 10, Issue 1, pp. 81-101.

Garcia, R., 2005. Uses of Agent Based Modeling in Innovation / New Product Development Research, The Journal of Product Innovation Management, Vol. 22, Issue 5, pp. 380-398.

Gomez-Mejia, L., Balkin, D., 2011. Management, Prentice Hall, 1st ed. USA.

Goodhue, R., Thompson, D.L., 1995. Task-technology fit and individual performance, MIS Quarterly, vol. 19, no. 2, pp. 213-236.

Hayes, J., 2010. The Theory and Practice of Change Management, Palgrave Publishers Ltd., 3rd ed. NY, USA.

Hiatt, J., 2006. A Model for Change in Business, Government, and our Community. Prosci Research Publications, Colorado, USA.

Hitt, M.A., Porter, L., 2011. Management, Prentice Hall, 3rd ed. USA. 
Ito, T., Abadi, S.M.M.J., 2002. Agent-Based material handling and inventory planning in warehouse, Journal of Intelligent Manufacturing, Vol. 13, Issue 3, pp. 201-210.

Kilic, H.S., Durmusoglu, M. B. 2012. Design of kitting system in lean-based assembly lines, Assembly automation, Vol. 32, No. 3, pp. 226-234.

Kotter, J.P., 1996. Leading Change, Harvard Business School Press, Boston, USA.

Kwong, C.K., Chen, Y., Chan, K.Y., Wong, H., 2008. The hybrid fuzzy least-squares regression approach to modeling manufacturing processes, IEEE Transactions on Fuzzy Systems, Vol. 16 (3), pp. 644-651.

Kwong, C.K., Chen, Y., Chan, K.Y., Luo, X., 2010. A generalised fuzzy least-squares regression approach to modelling relationships in QFD, Journal of Engineering Design Vol. 21 (5), pp. 601-613.

Lee, H., Ahn, S., 2008. Assessment of process improvement from organizational change, Information \& Management, vol. 45 , no. 5 , pp. $270-280$.

Lopez-Ortega, O., Lopez-Morales, V., Villar-Medina, I., 2008. Intelligent and collaborative Multi-Agent System to generate and schedule production orders, Journal of Intelligent Manufacturing, Vol. 19, Issue 6, pp. 677-687.

Ma, T., Nakamori ,Y., 2005. Agent Based Modeling on Technological Innovation as an Evolutionary Process, European Journal of Operational Research, Vol. 166, Issue 3, No 1, pp 741-755.

Martino, J., 1993. Technological forecasting: An introduction, The Futurist, vol. 27, no. 4, pp. 13-16.

Meredith, J., 1995. Technological Forecasting, John Wiley \& Sons, Inc., Indianapolis, USA.

Mesa, 2008. SOA in Manufacturing Guidebook, White Paper 27, A MESA International, IBM Corporation and Capgemini co-branded white paper.

Ministry of Environment \& Forestry, 2009. Sanayi kaynakli hava kirliliginin kontrol yonetmeligi, Ministry of Environment and Forestry, Turkey, Resmi Gazete 27277/3, July 2009.

Mohebbi, S., Shafaei, R., 2012. E-Supply network coordination. The design of intelligent agents for buyer-supplier dynamic negotiations, Journal of Intelligent Manufacturing, Vol. 23, Issue 3, pp. 375-391.

Monostori, L., Vancza, J., Kumara, S.R.T., 2006. Agent Based Systems for Manufacturing, CIRP AnnalsManufacturing Technology, Vol. 55, Issue 2, pp. 697-720.

Nejad, H.T.N., Sugimura, N., Iwamura, K., Tanimizu, Y., 2010. Multi agent architecture for dynamic incremental process planning in the flexible manufacturing system, Journal of Intelligent Manufacturing, Vol. 21, Issue 4, pp. 487-499.

OECD, 1995. The Measurement of Specific and Technological Activities: Proposed Guidelines for Collecting and Interpreting Technological Innovation Data, 2nd ed., Organization for Economic Co-operation and Development, European Commission and Eurostat, Paris, France, 1995.

Oztemel, E., Ayhan, M. B., 2008. Measuring technology adaptation in manufacturing systems, Proceedings of 6th International Symposium on Intelligent and Manufacturing Systems, E. Oztemel, Ed. Sakarya, Turkey: Sakarya University, Turkey, October 2008, pp. 636-648.

Oztemel, E, Ayhan, M.B., 2009. Measuring technological forecasting, Proceedings of 7th IEEE International Conference on Industrial Informatics, Cardiff, Wales, June 2009, pp. 49-53.

Oztemel, E., Ayhan, M.B., 2010. Measuring the capability of change in manufacturing processes, Proceedings of 7th International Symposium on Intelligent and Manufacturing Systems, E. Oztemel, Ed., Sarajevo, Bosnia \& Herzegovina, September 2010, p. Accepted to be published.

Oztemel, E., Ayhan, M.B., 2011. Yönetimsel Yenilikçilik Derecesinin Ölçülmesi, YAEM 2011, July, 2011, Sakarya, Turkey.

Peppers, M., Rogers, D., 2004. Managing Customer Relationships- A Strategic Framework. John Wiley \& Sons, Inc.,

Peters, R., Waterman, T., 2004. In Search of Excellence. Harper Business Essentials, USA.

Reddick, C.G., 2011. Customer relationship management (crm), technology and organizational change: Evidence for bureaucratic and e-government paradigms, Government Information Quarterly, vol. 28, no. 3, pp. 346-353.

Robbins, S., Coulter, M., 2009. Management, Prentice Hall, 10th ed. USA.

Roy, D., Anciaux, D., Vernadat, F., 2001. SYROCCO: A novel multi agent shop floor control system, Journal of Intelligent Manufacturing, Vol. 12, Issue 3, pp. 295-307.

Sabar, M., Montreuil, B., Frayret, J-M., 2012. An Agent-Based algorithm for personnel shift-scheduling and rescheduling in flexible assembly lines, Journal of Intelligent Manufacturing, Vol. 23, Issue 6, pp. 2623-2634.

Smit, P.J., Vrba, M., 2007. Management Principles, A Contemporary Edition for Africa, Juta \& Co. Publishers, 4th ed. Cape Town, South Africa.

Stemberger M.I., Jaklic, J., 2007. Towards e-government by business process change- a methodology for public sector, International Journal of Information Management, vol. 27, no. 4, pp. 221-232.

Taylor, F., 2010. The Principles of Scientific Management, Cosimo Publishing, NY, USA. 
Tureteken, O., Schuff, D., 2007. The impact of context aware fish-eye models on understanding business processes: An empirical study of data flow diagrams, Information and Management, vol. 44, no. 1, pp. 40-52.

Wenrong L., Xialong X., 2011. Study on Agent Based Innovation Behavior Research Technique, Procedia Engineering, Vol. 15, pp.3541-3545.

Wooldridge, M., 2009. An Introduction to Multi Agent Systems, John Wiley \& Sons Ltd. Publications, Glasgow, UK, $2^{\text {nd }}$ Edition.

Wren, D., Bedeian, A., 2009. The Evolution of Management Thought, John Wiley \& Sons, 6th ed. USA. New Jersey, USA. 